\title{
Study on Library Service Mode of Teaching and Research University under Big Data Era
}

\author{
Guishan Zhang ${ }^{1, a}$ \\ ${ }^{1}$ Jilin Agricultural University, Changchun, Jilin, 130118 \\ a email
}

Keywords: Big Data Area, Teaching and Research University, Service Model

\begin{abstract}
Big Data in Teaching Research University Library Management and Service to make teaching and research university library resources and services, service content, service environment, service methods and service models have had a profound change. Analysis of large data waiting for extended service mode conversion and data mining services and protection of library services resources on teaching and research university library services, discusses the next big data environment teaching and research university library service model . Keywords: big data; teaching and research university; library; service model With the rapid development of information technology and information society, the mobile Internet, networking, PC and various types of sensors produce huge amounts of data, people gradually notice that the data on social importance. When the solution to the collection, storage, computing, massive data analysis problems, make the massive data and computing power of the perfect combination, and all walks of life have a major impact on our society will enter the era of big data. As the library information resource center, only full use of all available resources of big data, the focus needs to establish a diversified active service mode, in order to meet the diverse needs of readers.
\end{abstract}

\section{Introduction}

Big data is not an exact concept, refers only to the initial information overload need to be addressed, beyond the general amount of memory in the computer processing of the data used. Up to now, large data nor the formation of a uniform definition in the industry, it is only a general description. And I personally agree with the following view: huge amounts of data, also known as big data or mass data is due to the number, size too large by mainstream software tools to complete the collection, processing, analysis, within a reasonable period of time to help organize and use by more rational decision-making information. Big data has a huge amount of variety, processing speed, low-value-density characteristics. The concept of big data, big data has pointed to infiltrate all areas of today's society has become an important social resource, Big Data era has arrived.

\section{Big Data Library Services}

Respect era of big data, data storage library, data management and data applications are under attack, and the use of various types of data for the library reader service strategy pattern has changed.

In the past, the library service resources are mainly collections of books, journals, newspapers and various electronic resources, as well as some open access to resources on the network and brothers shared library resources. In the era of big data, not only these resources Library structured data and semi-structured data portion of the required services, but also other semi-structured data (such as the reader's records, query logs, records and other mobile terminal use) and vast amounts of unstructured data (such as audio, video, images, hypermedia, micro-channel, sensor data, etc.), as well as through these semi-structured data and unstructured data summarized in favor of improved regularity library services, decision-making and value of the data.

Way traditional library service is to provide a variety of resources to readers, information services and carry out various cultural activities. The era of big data, teaching and research university library services become more complex and diverse ways, traditional service toward 
deepening, fine direction, but also open up many new service. Library Integration carding have large data mining through the intelligent matching all interest in reading, for readers to read immersion depth study to provide content and tools, providing data integration services is the development direction of library services. Such as by borrowing records of readers, reading preferences or retrieve records analysis research readers initiative recommend good books or research data to the reader in this category.

Traditional service data library is mainly all kinds of museum collections resources, open access resources and sharing of resources, structured data types is relatively simple, relatively simple structure. The era of big data, core assets of large data library services, increased data types, complex structure. This requires that the library must have certain information collection, storage and processing capacity, to take advantage of related equipment to handle large data, which summed up the correct, regular information in order to improve services for libraries, improve service quality. Library Readers will usually be three-dimensional data, comprehensive collection, processing, analysis and mining, these behaviors may lead readers to the illegal interception of data privacy, theft, tampering and use. Therefore, the library must start to protect and safeguard rights and interests of readers, consciously abide by relevant laws and regulations, long-term mechanism to protect reader privacy formation.

\section{Diversified Teaching Research University Library Service Model under the Big Data}

The era of big data, teaching and research university library is still complex library, borrow, inquiries, communications, and other traditional reference services is still an important part of library services, but these services will vary by application and toward big data fine development of direction. At the same time, the library will be many new services, such as personalized service, data visualization.

Libraries have a large quantity of books, newspapers and various electronic resources, coupled with massive open shared resources on the network and access to resources, which constitute a large data library is the foundation to carry out all types of library services. Big Data era, the library through the OPAC retrieval system, a large number of retrieved records, loan system in borrowing records, recommended purchase systems Readers Choice bibliographic records, the official micro-blog and readers demand data micro-channel on the network to carry out excavation, analysis, accurate positioning needs of readers; recorded by using electronic resources, analyze the situation readers to use electronic resources. At the same time, but also pay attention to gathering open to meet the needs of readers access to shared resources and resources of the National Library and the world. Armed with this information, library collections can be combined with resources, open access types and quantities of resources and sharing of resources, resource types, most readers purchase demand, promote rationalization library resources, data resources to establish a diversified system needs to focus, to satisfy readers demand.

The era of big data, domestic and international library community in knowledge services to actively explore and practice, until now has formed a relatively complete library knowledge service system, on the basis of traditional services generated a lot of personal, professional, team ways of innovative services and mode. Currently, the traditional information consulting, reference, information literacy education and other services remains an important way of library knowledge service. When these services are based on the information needs of the mass readership data analysis, targeted services have been strengthened, quality of service levels and the effect has been significantly improved. Meanwhile, the library collection, collation, analysis and utilization of large data base to achieve a knowledge services innovation. First, through mobile phones, PDAs, E-book and other mobile devices to achieve a mobile information service, the mobile phone network to achieve the organic integration of computer networks and television network three networks, making mobile services more comprehensive knowledge, timely and convenient; the second is through automation technology applications library automated information services, such as self-service library inquiry system, the establishment of virtual librarians; third is the application of knowledge discovery system to meet the reader study, learning knowledge needs; Fourth, when 
based on the content when demand analysis of large data applications and the Library knowledge service perfect fusion will produce a library of knowledge consulting services, it will become the advanced mode library in the era of big data information services.

Library Service Resources also will be a huge change, not just a variety of resources owned by the museum, more open data network, microblogging, letters and other media access and other library or information center shared data. Therefore, the library should strengthen cooperation with other libraries, information centers, while actively working with archives, museums, government agencies to cooperate with the data and selectively companies, academic search, "Encyclopedia" website, "know" service docking and other cooperation with the information center, full of big data resource sharing. Libraries cooperate with other information resource center, complementarity and common service model to create synergies, give full play to the role of big data to improve library services.

Mainly traditional library service is a common, generalized services, services mainly for all readers to meet popular demand, as measured by service quality and effectiveness. The era of big data, cloud services and application development platform, cloud computing and big data technology, making the collection of unstructured data, analysis and application can be achieved. Through the large data mining, you can easily get an individual library readers demands, learning needs, research and other information, information services can be based on these information needs, collect data associated with large data resources in the library, and then organize, summarize and actively pushed to the reader, to meet the individual needs of readers. This library is an important part of deepening the service, but also an important manifestation of the quality of service enhancements.

Visualization is the theory using computer graphics and image processing technology to convert data into graphics or images displayed on the screen and interact with the process, methods and techniques, research data representation, data processing, decision analysis and other issues of integrated technology.

Era of big data, data showing the way has been greatly improved, teaching and research libraries can be data-specific operations to visually presented to the reader, so that analysis the reader data more vivid, intuitive, concrete, saving the user to understand data the relationship between time and improve service efficiency and depth of teaching and research university libraries. And some of the data can provide a direct basis for decision-making to the reader, such as the way large screen displays the number of libraries in the Reading Room, crowded areas displayed in red, the reader can be based on the display screen, select the appropriate learning region.

\section{Conclusion}

In short, the curtain has opened the era of big data, big data is becoming teaching and research university library core assets, its application allows library service resources, service mode a dramatic shift. Teaching and research university libraries only make full use of the museum, the network, the establishment of other libraries and information resource center of a large data base of diversified services model, seeking various forms of knowledge services, the initiative to push the individual needs of readers, to achieve the highest possible service data visualization, it provides readers with sophisticated, professional, personalized service and meet the popular demand of the reader at the same time, to meet the individual needs of readers, improve the quality of library services and the level of teaching and research university .

\section{References}

[1] Zhang Wenyan, Wu Ruiyuan. Library era of Big Data [J]. Library and Information, 2012, (6) Zhang Wenyan: 15-19.

[2] Jiang Shan, Wang Gang. Revelation Gang large data library [J]. Library Work and Research, 2013, (4): 52-54. 
[3] Su Rong. Based digital Big Data Library Information Service [D]. Huazhong Normal University, 2014.

[4] Liu Jinling. Research era of big data Library Information Service [D]. Southwest University of Science and Technology, 2015. 